\title{
Empirical Study of Technological Factors Being Involved in Income Distribution
}

\section{--An Example of Gansu Province}

\author{
Liqun $\mathrm{Li}^{1}$ \\ ${ }^{1}$ School of Economics, Northwest University for Nationalities, Lanzhou, China \\ Correspondence: Liqun Li, School of Economics, Northwest University for Nationalities, Lanzhou 730124, China.
}

Received: March 17, 2017

Accepted: March 30, 2017

Online Published: April 20, 2017

doi:10.5430/ijfr.v8n2p182

URL: https://doi.org/10.5430/ijfr.v8n2p182

This work was supported by the Fundamental Research Funds for the Central Universities of Northwest University for Nationalities (Grant No. 3192015115).

\begin{abstract}
Involvement of technological factors in income distribution according to their contributions is an intrinsic requirement of the market economy, and also an objective requirement for promotion of technological innovations and realization of effective allocation of resources. However, many problems emerged in China's enterprises and public institutions, higher education institutions and research institutes during their growth and development, these problems include: "Insider control", "59 Years Old Phenomenon", Low Work Efficiency and severe brain drain etc. These issues were caused by many factors, one key factor is the incomplete distribution incentive mechanism which is, in fact, an ignorance of the value of human capital. Through field investigation of technological factors involving in income distribution in Gansu Province, this article analyzed related data, had a conclusion and proposed some issues in the distribution mode.
\end{abstract}

Keywords: technological factors, income distribution, empirical study, Gansu Province

\section{Theoretical Study}

Ever since 1980s, knowledge economy had made its first appearance in developed countries, and it entered a rapid development period in the 1990s when the functions of knowledge and technologies were shown in income distribution. One change of distribution was the introduction of three distribution theories, i.e. Sharing Economy, Economic Democracy and People Capitalism. The Sharing Economy Theory was introduced by an American scholar ML Weitzman in 1984, the core of this theory is that the salary standard shall be determined based on the "sharing ratio" of marginal efficiencies of labor and capital, allowing labors and capitals to share the profits of enterprises together. The Economic Democracy Theory is an economic theory introduced based on employee stock option plan of enterprises and employee participation system etc. The People Capitalism was introduced by L Baddon of the UK, its core is that the workforce can gain equivalent power as the capitalist by sharing enterprises' profits and ownerships. Among these three distribution theories, the Sharing Theory is the most influential one. It has five concrete forms in reality: enterprise profit sharing system, enterprise value sharing system, enterprise ownership sharing system, enterprise management rights sharing system and reward system for contribution of professionals. The income distribution system we are discussing now belongs to this Sharing Theory.

Two perspectives coexist in China regarding basis for involvement of technological factors in income distribution. One school supports distribution based on contribution, including the distribution system based on contribution in the creation of use value, distribution system based on contribution in the creation of surplus value and distribution system based on the contribution in contribution rate. The other school advocates distribution based on ownership, i.e. whoever owns or controls the means of production has the right to gain benefits through the ownership or right of possession on means of production. 


\section{Empirical Analysis of Involvement of Technological Factors in Income Distribution in Gansu Province}

Many specialists and scholars raised several different views regarding the involvement of technological factors in income distribution, but basically all of them are originated from one single method, study on combination of distribution methods is lacking. The respondents of this investigation are scientific and technological personnel from enterprises, higher education institutions and research institutes of various (cities and states) of Gansu, the final responses were processed and analyzed using SPSS statistical software. A total of 1,000 questionnaires were handed out and 781 effective ones were collected, accounting for $78.10 \%$ of total questionnaires. Among those collected effective questionnaires, 642 came from enterprises, accounting for $82.20 \%, 121$ came from research institutes, accounting for $15.49 \%$ and 18 came from institutions of higher education, accounting for $2.30 \%$. The results showed that $93.75 \%$ of the respondents think that technological factors shall be involved in income distribution in various forms.

\subsection{Analysis of Problems in Implementing the Scientific and Technological System}

The investigation showed that the most prominent problem in the scientific and technological system as believed by enterprises, higher education institutions and research institutes is the lack of capability to attract and sustain excellent talents $(55.13 \%)$. Other problems of descending order of concerns are: lack of high-standard talents and academic and technological leaders (53.84\%); scientific research funds cannot be guaranteed, the development potential is lacking $(27.68 \%)$; lack of funds investment, lack of management experiences (23.57\%); poor awareness of employees (18.69\%); incomplete matching systems and constraints of management system (18.44\%); non-standardized market environment and poor market capacity (17.95\%); lack of proper channels for settlement of dispersed personnel (15.22\%); lack of professional technical services of scientific research institutes (12.14\%) as well as endowment and medical issues etc. (11.80\%).

We can see from here that retaining talents is a humanistic benefic which cannot be overlooked to promote scientific and technological progresses. While the inclination of income distribution system amounts an important way to arouse the enthusiasms of scientific and technological talents.

\subsection{Analysis of Basis for Technological Factors to Be Involved in Income Distribution}

At present, most enterprises, higher education institutions and research institutes use contributions of scientific and technological personnel as the basis for involvement of technological factors in income distribution, which accounts for $87.9 \%$, while only $10.3 \%$ of units implement the income distribution system based on the posts and titles of scientific and technological personnel, this basis for income distribution is rather monotonous.

\subsection{Analysis of Methods of which Technological Factors Are Involved in Income Distribution}

According to this investigation, the most common distribution methods are one-off rewards and profit drawing, proportions of these two methods are $53.4 \%$ and $32.8 \%$ respectively. Special allowance for talents (such as housing allowance) accounts for $19 \%$, technology investment accounts for $17.2 \%$, profit drawing accounts for $20 \%$, contract of scientific and technological projects accounts for $14.7 \%$, few enterprises adopt stock reward, stock rights offering, stock option and dividend of scientific and technological achievements, their proportions are merely $3.5 \%, 3.8 \%$, $3.1 \%$ and $5.2 \%$ respectively (Table 1 ).

Table 1. Analysis of methods of which technological factors are involved in income distribution

\begin{tabular}{ll}
\hline Distribution methods & Proportion\% \\
\hline one-off rewards & 53.4 \\
profit drawing & 32.8 \\
scientific and technological projects & 14.7 \\
Special allowance for talents & 19 \\
profit drawing & 20 \\
technology investment & 17.2 \\
stock rights offering & 3.5 \\
stock option & 3.8 \\
dividend of scientific & 3.1 \\
technological achievements & 5.2 \\
others & 3.7 \\
\hline
\end{tabular}


Most enterprises, higher education institutions and research institutes adopt the short-term distribution of one-off rewards, more than half of the investigation samples adopted this method, this adoption is closely related to the simple and convenient nature of one-off rewards. Followed by medium to long term distribution method, profit drawing, but the ratio of profit drawing is nearly $20 \%$ less than one-off rewards. Very few units employ long term distribution methods such as stock option, stock rights offering, stock reward and technology investment etc., proportions of scientific and technological projects contracts and achievement transformation are small, this might be related to the complexity of these distribution methods. All in all, most enterprises, higher education institutions and research institutes mainly concentrate on short-term distribution methods only and lay insufficient attention to long-term ones.

\section{Analysis of Implementation Results of Technological Factors' Involvement in Income Distribution}

\subsection{Incentive Effects of Distribution Methods and Satisfaction Analysis}

Only $4.3 \%$ of all scientific and technological personnel participated in the investigation think the incentive effect is good, only $39.8 \%$ think it is fairly good. However, $34.4 \%$ and $15.1 \%$ of them think the incentive effect is normal and poor, and there are $6.5 \%$ of them think that the incentive effect is really poor. Scientific and technological personnel are largely unsatisfied with the current income distribution methods. Only $4.3 \%$ satisfied, $38.7 \%$ are largely satisfied, yet respondents with normal, low and very low satisfaction degrees are $32.3 \%, 18.3 \%$ and $6.5 \%$ respectively (Table 2).

Table 2. Incentive effects of distribution methods and satisfaction

\begin{tabular}{ll}
\hline Incentive Effects & Proportion\% \\
\hline good & 4.3 \\
fairly good & 39.8 \\
normal & 34.4 \\
poor & 15.1 \\
really poor & 6.5 \\
\hline
\end{tabular}

3.2 Analysis of the Optimal Income Distribution Method with the Best Incentive Effect on Scientific and Technological Personnel

Among all scientific and technological personnel participated in the investigation, 33.3\% of them regard profit drawing as the method with the best incentive effect, followed by technological investment which accounts for $21.4 \%$, and scientific and technological project contract which accounts for $20 \%$. Only $8.7 \%$ of the respondents feel the one-off reward has the best incentive effect among all, while that figure for stock reward, stock rights offering and stock option is $4.3 \%$ only. $4.7 \%$ respondents prefer the technological achievement dividend while $3.3 \%$ of prefer talents special allowances.

It is pretty apparent that two medium to long term income distribution methods, i.e. profit drawing and technological investment, are of the best incentive effect. Scientific and technological project contracts also show good incentive effect. However, short-term distribution method such as one-off reward does not intrigue many scientific and technological personnel with other forms of stocks and scientific and technological achievements dividend incentive has even poor attraction.

\subsection{Analysis of Customized Combination of Distribution Methods and Willingness of Scientific and Technological Personnel}

As for the question "should scientific and technological personnel be allowed to choose the combination of distribution methods themselves?", 76.3\% of the respondents responded "Yes", only $23.8 \%$ of them think it is inappropriate. We can see that most scientific and technological personnel think it is rational and necessary to be granted with the right to choose their combinations of distribution methods, this further supports the idea of the customized combination of distribution methods raised by this article. And as for their willingness to try out the customized combination of distribution methods, a majority of them (86\%) conveyed their willingness, indicating that the introduction of this customized combination of distribution methods is backed by reality and thus has a market. 


\section{Conclusion}

For enterprises, institutions for higher education and research institutes, technological factors shall not be involved in income distribution in a single way, instead, it shall be a combination of many distribution methods. Only by that, shortages of different income distribution methods can be remedied and achieve the greatest incentive effect on scientific and technological personnel. The combination of various income distribution methods shall reflect the principle of combining short-term incentives and long-term incentives. Units of different natures shall employ different distribution methods and combinations for their scientific and technological personnel. Allowing scientific and technological personnel to choose their distribution scheme based on their needs and differences can significantly arouse their enthusiasm and creativity. Stock rights and dividend incentive policies shall be greatly promoted in research institutes and higher education institutions.

\section{References}

Athanasius. A. (1995). Income Distribution Theory, (Chinese Translation Version). The Commercial Press.

Chen, K. (2001). Distribution According to "Knowledge" under Socialist Market Economy. Academic Journal of Yunnan University of Finance and Economics, 2.

Chen, Y. (2000). A Few Thoughts Regarding Involvement of Technological Factors in Corporate Distribution. Shanghai's Enterprises, 10.

Han, B. (1998). Salvation of the Western World---Changes and Contributions of Modern Western Income Distribution System. Shandong People's Publishing House.

Third Plenary Session of the Twelfth Central Committee of the Central Committee of CCP. Decisions of the Central Committee of CCP on Reform of the Economic System.

Zhou, Z. (2003). Income Distribution---Analysis of China's Economy 2001-2002. Shanghai People's Publishing House. 